\title{
Application of GIS in Rural Planning
}

\author{
Leng Hao Ran and Zhou Bo
}

\begin{abstract}
Based on analyzing the necessity of using GIS in the new rural planning a variety of thematic maps were used to study the application of GIS in the new rural planning. The application of GIS in country planning and the superiority of using GIS in rural planning were discussed. It was proved that the powerful spatial analysis of GIS efficient mapping functions scientific planning and management technology were applied to the new rural planning study. Through reasonable and effective application of GIS, the scientific, practical, normative and accuracy performance of new rural planning were improved.
\end{abstract}

Index Terms-Rural areas, GIS, slope analysis.

\section{INTRODUCTION}

In recent years, with the rapid development of economy, planning idea and concept has been from the city into the countryside. At the same time, due to the impact of policies, speed up the building of a new socialist countryside, become the urgent request must understand "three rural issues" and the construction of a harmonious society, it is directly related to the new period of agricultural modernization development and rural economic prosperity. In the new rural planning, the traditional method cannot meet the scientific planning and analysis needs of tightness. Since the development of GIS since the nineteen sixties medium-term, has been used for resource monitoring and survey, regional planning, surveying and mapping, disaster assessment and prediction, environmental protection, tourism planning and management, military and other fields and export. In the new rural planning, GIS with its powerful spatial analysis and efficient data query capabilities, highlights its advantages in rural planning, the new rural planning more scientific, reasonable. Therefore, the application of GIS is the planning of the recognized and studied by many researchers. However, application of city planning and rebuilding has less research on rural planning [1].

The application of geographic information system, planning projects in the new rural construction of Hebei province Yixian County township as an example, presents how to for the new rural construction planning accurately, quickly provide the spatial analysis data, provide the basis and foundation of reliable work and for the new rural construction planning, and improve the planning of science and rationality, the demonstration for new rural construction in Hebei province [2].

Manuscript received January 18, 2013; revised March 25, 2013

The Authors are with the Jiangxi Normal University, Nanchang, China (e-mail: 524170946@qq.com).

\section{ANALYSIS ON THE NECESSITY OF THE APPLICATION OF} GIS

\section{A. The Shortcoming of the Traditional Planning Method}

Planning of new socialist countryside, first of all need to acquire the basic geographic information, land use, infrastructure, resources and environmental protection, information and other aspects of the information and data, then the data analysis and research discard the false and retain the true, planning and design. The most important is the fundamental geographic information data collection, including topography, population information, traffic information, Social and economic statistics. The use of the existing information must be analyzed and checked, in order to improve the accuracy of the data in geographic information system. Because the socialism new rural planning should not only reflect the characteristics of rural culture and rural landscape, but also to achieve one village is tasted, also in accordance with the new rural planning standards and requirements of scientific planning, it needs comprehensive treatment and analysis of large amounts of data[3].The past regional planning needs to draw the map and calculating data by hand, not only time-consuming and laborious, cannot guarantee the data accuracy, but also in spatial analysis and query retrieval is even more difficult to achieve. The traditional planning method in statistical data and display is also very difficult to meet the needs of modern planning.

\section{B. GIS Mapping of Low Investment, High Yield}

Massive waste of time and energy of the GIS solves the traditional manual data processing, and use GIS to establish the map database can reach one input, multiple $\} \mathrm{H}$ effect. It can not only output the elements of topographic map for the user, and can be based on user needs according to the power output and the output of various attributes such as layered thematic map, such as map etc..

GIS mapping method is better than the hand Ding traditional cartography method to facilitate more flexible, based on the map, we can quickly produce a variety of high quality planning needs of users using graph by adding special data, such as the development of villages and towns, villages and towns plan project planning chart. In the production planning map, can choose appropriate symbols and colors from the symbol and color library according to the actual need, make the best maps generated outstanding special effects and characteristics [4].

Traditional planning methods only single to make various planning map, to manually create and modify tables, for planning map update is even more difficult to achieve. GIS can not only low cost but high to quickly generate a variety of programming with graph and table data, but also can 
realize the dynamic data updating [5].

Thus, G1S reduces the consumption of time, manpower and material resources planning, greatly improves the accuracy of planning operation efficiency and information, and the implementation of the planning of science, rationality and operability. Therefore, GIS is the foundation of an indispensable tool in new rural planning.

\section{Analysis of the Statistical Data in GIS Advantage}

Because the rural economic structure dominated by agriculture, the rural planning strictly protect arable land is placed in the core position, especially the occupation of cultivated land is prohibited. In the new rural planning and design process, first of all need to population, land use, the level of economic development were analyzed, and the index of planning residential layout, construction area of 121, density, volume rate were calculated. Methods the manual computation efficiency is low, long time consuming, high error rate, directly affect the quality and schedule planning and design [6]. GIS this situation will be completely changed, its database technology as the support, to achieve the combination of graphics and attributes, and stratification and classification of data processing. According to the different attribute or layer analysis and index calculation on the data, not only saves the planning and design personnel of physical strength and time, but also greatly improve the calculation accuracy, the planning of science and rationality.

\section{The Advantage of GIS in the $3 D$ Visualization}

Three-dimensional visualization is used to describe a Ding and display characteristics of surface and underground space with many phenomenon, is a means to describe and understand the model, is a form of data. Digital terrain model (Digital Terrain Model, OTM) is the expression of terrain surface morphology attributing information of digital, with a space of digital description. Realization of 3D visualization of terrain by DTM or DEM module in GIS [7].

In practical application, the $3 \mathrm{D}$ visualization technology cannot only the surface of the planning area of the display and description, and the geological environment of underground can also display and description. This technique is often used in the analysis of geological environment analysis, resource reserves. The current research on visualization is more extensive, such as water conservancy and hydropower, geological exploration, city planning etc.

In traditional planning, plane design and rendering drawings can neither give designers and users to provide true feeling and scene, easily hidden risks of planning, and the design cycle is long, poor effect, high cost, low precision. In the socialism new rural planning, to realize the $3 \mathrm{D}$ visualization of terrain and buildings using digital terrain model function of GIS and orthophoto map or picture, can be visualized analysis of engineering pipeline is not visible. At the same time, by using the GIS 3D visualization technology, planning and design personnel can be analyzed from the topographic and geological conditions, put forward reasonable planning, but also can real-time, interactive effect of inspection planning, scientifically and reasonably carry on planning and design, to ensure that the design is feasible, and these are the previous planar drawing and building model difficult to achieve.

\section{E. GIs in the Planning Implementation and Management Advantage}

In the traditional planning management, planning departments tend to use file system or CAD graphics data management planning data. However, the traditional management mode cannot automatically complete consistency and data updates according to the planning adjustment. In the traditional conditions, each round of adjustment planning means planning personnel to statistics and the drawing work, it will spend a lot of time and energy. However, with the rapid development of economy, many cities, town planning adjustments to speed up the frequency, at the same time the planning approval and implementation has the urgent need in time, further compression cycle planning adjustment. So easily lead to insufficient planning rough and Ding as depth, and ultimately hurt the overall interests of the comprehensive development of city or town and people [8]. At the same time, the traditional planning management of redundant and inefficient, not only causes the data update and query is more difficult, but also resulted in the graphics and attributes from, let the miscellaneous file takes up a lot of space, increase the management burden.

GIS in the planning of the management in the process of changing the traditional planning results lack of continuity of the drawings, and make sustainable update data, to realize the dynamic management of planning data; at the same time, breaking the past lack of auxiliary information fast and accurate analytical tools under the condition of social, economic and other subjective based data analysis: furthermore, mass data using GIS technology, scientific management and comprehensive analysis of the spatial characteristics, ensure the data real-time and accurate, scientific, accurately reflect the current situation and development trend of the planning area, and put forward the reasonable decision.

\section{Study ON APPLICATION OF GIS Mode IN THE NEW RURAL PLANNING}

\section{A. The Overview of the Study Area}

Dule to ownership is located in Baoding City, south of Yixian County, from the county town of $37.3 \mathrm{~km}$, and rural roads have been wearing, rural area of 34.7 square kilometers domain, and $8.6 \mathrm{~km}$ long, $8.4 \mathrm{~km}$ wide. Located in North East Taihang Mountain, exposed bedrock is limestone, dolomite. Surrounded by mountains, and the terrain was the East West High low, only is the Central Plains, mountainous area accounts for $75 \%$, Hirakawa $25 \%$, above the average altitude of $600 \mathrm{~m}$ village, North Canal flow.[9]

\section{B. Elevation Analysis}

Digital elevation model is in digital form by certain structure together, said the distribution of real terrain feature space model is also the terrain size and ups and downs of the digital description. Study area the height information analysis has a significant impact on the layout and space layout, especially the elevation in mountain area analysis is more important. Terrain conditions directly affect the 
planning layout, road direction, pipeline layout, and building combined arrangement, Xiang domain contour, shape, disaster prevention etc. Therefore, elevation analysis is an important factor in construction site selection and planning.

Digital elevation model can display the terrain changes and distribution of the study area, the intuitive planners can grasp the village planning from the whole idea. On the basis of using digital elevation model diagram, according to the relationship between terrain, landform and architectural features, a housing adapted to characteristics of mountain form land and commercial land are organized in the mountain, slope, and the need for administrative office, to the hotel industry background, two types of residential land located in the foothills, some other building density and volume is large and the flow of land arrangement in the lower zone.

\section{Slope Analysis}

The vertical height of slope is a slope and the horizontal width ratio. Slope indicates a tilt of the local surface slope, directly affects the size and strength of surface material flow and energy conversion, the important factor and the slope is also restricts productivity space layout [10].

The study area around the ups and downs of the larger, higher than the eastern, middle is reduced by the saddling mountains to the north and South sides. In the study area, $0 \sim 10$ slope degree areas are located in saddle mountain sides; gradient distribution in the region of 10 20 less, transition area is usually dispersed in peace star mountain, slope greater than 20 degrees is not suitable for land distribution in the surrounding area construction, the East and South and East. Look for site selection and construction of the construction of the slope from, $0 \sim 1$, because of the too flat is not conducive to the drainage; 1 5 degrees slope, topographic condition is ideal, need only minimal cut; 5 10 degrees slope, land formation work, increase the engineering quantity; 10 15 degrees slope, in the construction of residential units, need was the wrong layer and parallel with the contour, so as to reduce the excavation and backfilling of earthwork, also need to build retaining walls and other protective measures; more than 15 degrees slope, residential requires the use of special architectural style building, such as supporting engineering. In order to improve land use rate, the gradient of 25 degrees and 25 degrees slope designated as no construction area.

Analysis of terrain based on slope, in the planning and construction, the construction of mountains, suit one's measures to local conditions, strip layout, well-proportioned, and the use of relatively flat land for residential and green, leisure and other public facilities land use based on the conservation and protection of arable land, forming a unique mountain landscape. In agriculture, the flat terrain slope in the land use degree 10 20 of the sunlight greenhouse construction adequate and livestock farming area, promote the development of agricultural economy.

\section{Slope Analysis}

Slope is an important terrain feature of local climate, the climate of slope is an important terrain feature of local climate, the climate of solar radiation, temperature, evaporation, moisture and vegetation, soil, hydrology and profound influence, but also affecting the growth of crop, frosty period, temperature, surface moisture content. Because in sunny slope, solar radiation time is long, the temperature difference between day and night; in the shady slope, small diurnal temperature range, with the majority to sunny, can get enough sunshine time. Conversely, different slope vegetation types makes the exchange of heat and moisture in time and space, also changed significantly, and the temperature, humidity of the study area changes, and the effect on light, precipitation. With the sun plant and shade plants on the thermal requirements of different slope and the distribution, determine the planting area, more scientific and reasonable to carry out agricultural and ecological planning. So in the township, sunny planting crops and fruit trees in the north, and should be planted cypress trees and some shrubs. To analysis function for garden plant species provide the basis for the choice of the slope by GIS. In the landscape, according to the different light requirements of different plants, the garden plants are divided into positive plants (such as pine, sycamore) and shade plants (such as Du Ying. loquat) two categories. The positive plants species in sunny areas, lack of light and shade tolerant species in plant shadow zone. The side slope analysis is shown in figure 3. [11]

\section{E. Confluence Analysis}

The bus is the formation of precipitation water collection process, from the point to the watershed outlet, including slope conflux and river confluence of 2 sub stage. The bus is mainly influenced by rainfall and underlying surface factors. Rainfall characteristics refers to a change in temporal and spatial distribution of rainfall and rainfall intensity, water flow along the length and under regulation directly affects the size of watershed confluence process; the main underlying surface factors refer to the basin slope, channel slope, water shape, drainage density and soil and vegetation[12].

Planning for the surface runoff is composed of surface runoff in the planning area to determine the value of, when a runoff is greater than a specified flow, that it might bring some disaster, will be in the week with the establishment of protective measures, when runoff in another area that can be built. An ecological corridor in runoff flows, when less than a certain value of runoff flow cannot consider. Method of runoff calculation in the planning area is the traditional manual calculation using contour, not only large workload and time consuming. Runoff in the GIS analysis can save a lot of time for the planners to provide accurate data, runoff, which enables planners to make scientific planning scheme.

\section{CONCLUSION}

Through the research on the application mode of GIS technology alone le in regional planning, we can see the basic data of GIS technology in detail, reliable, accurate basis for analysis, spatial query, spatial analysis can be as the analysis tool, with intuitive chart for analysis results, to provide scientific and rational basis for planning staff to provide strong decision, support for fast, efficient, scientific planning of new countryside. In the future, the new rural development will play a very important role. At the same 
time, due to the application of GIS in the new rural planning and obvious advantages, the new rural construction planning more scientific and reasonable, to a certain role model for new rural construction in Hebei province.

\section{REFERENCE}

[1] S. J. Li, "Integration and coordination of the," Tianjin University, 2009.

[2] R. J. Li, Principle of geographic information system.

[3] Y. Li, "Emergency path planning method of 3D based on GIS of," International City Planning 2007, vol. 22, pp. 99-102.

[4] X. D. Song, "Some non technical problems and countermeasures of city planning application of geographic information system," City Planning in the Industry, vol. 2, pp. 41-43, 1997.

[5] J. Li, "DIS in the reconstruction planning of city village in the application research of city planning," vol. 33, pp. 89-92, 2009.

[6] Y. Q. Zhou, "GIS's city planning thematic mapping based on city planning," vol. 2, pp. 27-29, 1995.

[7] J. Liu, "Water conservancy and hydropower engineering geological study of 3D modeling method of Science in China," vol. 37, no. 3, pp. 455-466, 2007.

[8] Computer engineering and design the GIS data visualization based on research, vol. 29, no. 4, pp. 3757-3762, 2008.
[9] Had rows of geographic information system in city design in the application of engineering of Surveying and mapping, vol. 14, no. 4, pp. 69-76, 2005

[10] X. F. Qiao, "City planning in the application of GIS analysis Shanxi water conservancy science and technology," vol. 20, no. 6, pp. 25-29, 2005

[11] X. C. Wu, The principle and method of geographic information system Beijing, Publishing House of Electronics Industry, 2002.

[12] S. X. Yan, "Shanxi water conservancy science and technology of computer simulation of reservoir real-time flood forecasting and dispatching," vol. 2, pp. 50-53, 2005.

Leng Hao Rao comes from Xiushui, Jiangxi, China. He was born in January 1981. He graduated from Nanchang University, and obtained a master's degree in engineering in 2010. He is mainly engaged in architectural design and theory research. He is teaching work in Jiangxi Normal University, and gets a lecturer title. His current research topic is art fund project, research on city water revetment ecological restoration.

Zhou Bo was born in Mach 1980, Fengcheng, Jiangxi, China. He got his master degree from Nanchang University. He mainly researches direction for architectural design and theory, lecture, working for Jiangxi Normal University. He is teaching work in Jiangxi Normal University, and gets a lecturer title. His current research topic is school youth fund projects, research on new rural construction planning study. 